\title{
Time and energy constraints and the relationships between currencies in foraging theory
}

R. C. Ydenberg

C. V. J. Welhom

Behavioral Ecology Research

Group,

Department of Biological

Sciences,

Simon Fraser University,

Burnaby, British Columbia

V5A IS6, Canada

R. Schmid-Hempel P. Schmid-Hempel ETH Zürich,

Institute of Terrestrial

Ecology,

Grabenstrasse 3,

CH-8952 Schlieren (Zürich),

Switzerland

\section{G. Beauchamp}

Behavioral Ecology Research

Group,

Department of Biological

Sciences,

Simon Fraser University,

Burnaby, British Columbia

V5A 1S6, Canada

Received 4 May 1999

Revised 20 October 1992

Accepted 10 November 1992

$1045-2249 / 94 / \$ 5.00$

(C) 1994 International Society

for Behavioral Ecology

Measured foraging strategies often cluster around values that maximize the ratio of energy gained over energy spent while foraging (efficiency), rather than values that would maximize the long-term net rate of energy gain (rate). The reasons for this are not understood. This paper focuses on time and energy constraints while foraging to illustrate the relationship between efficiency and rate-maximizing strategies and develops models that provide a simple framework to analyze foraging strategies in two distinct foraging contexts. We assume that while capturing and ingesting food for their own use (which we term feeding), foragers behave so as to maximize the total net daily energetic gain. When gathering food for others or for storage (which we term provisioning), we assume that foragers behave so as to maximize the total daily delivery, subject to meeting their own energetic requirements. In feeding contexts, the behavior maximizing total net daily gain also maximizes efficiency when daily intake is limited by the assimilation capacity. In contrast, when time available to forage sets the limit to gross intake, the behavior maximizing total net daily gain also maximizes rate. In provisioning contexts, when daily delivery is constrained by the energy needed to power self-feeding, maximizing efficiency ensures the highest total daily delivery. When time needed to recoup energetic expenditure limits total delivery, a low self-feeding rate relative to the rate of energy expenditure favors efficient strategies. However, as the rate of self-feeding increases, foraging behavior deviates from efficiency maximization in the direction predicted by rate maximization. Experimental manipulations of the rate of self-feeding in provisioning contexts could be a powerful tool to explore the relationship between rate and efficiency-maximizing behavior. Key words: Efficiency, energy gain, foraging strategies, provisioning. [Behav Ecol 5:28-34 (1994)]

$\mathrm{T}$ he economic analysis of foraging behavior is based on the assumption that foragers behave so as to maximize a goal function assumed to be linked to fitness (Stephens and Krebs, 1986). The goal function incorporates costs and benefits and is referred to as a fitness currency. Studies of foraging behavior have considered a variety of currencies including the rate of energy gain and energetic efficiency, defined as the ratio of energy gained over energy spent while foraging. Other currencies, largely variations on the previous themes, have also been considered (e.g., family gain: Kacelnik, 1984; overall delivery rate: Houston, 1986; see also Fagerström et al., 1983; Montgomerie et al., 1984). Different currencies have made successful predictions in different studies, but the rationale underlying the use of one currency instead of another is not always clear.

Efficiency was recognized and discarded as a potential currency in some of the first papers on foraging theory. The argument for rejecting efficiency as a currency goes as follows: If a forager can gain $2 \mathrm{~J}$ for the expenditure of $1 \mathrm{~J}$, the efficiency is 2 . (If we consider net intake, efficiency becomes $2 \mathrm{~J}$ $-1 \mathrm{~J} / 1 \mathrm{~J}=1$.) An alternative offering $5 \mathrm{~J}$ for the expenditure of $3 \mathrm{~J}$ gives greater gain but lower efficiency $(5 \mathrm{~J} / 3 \mathrm{~J}=1.7)$. If we consider net intake, efficiency becomes $(5-3) / 3=0.7$ (this does not change the argument). The second choice would seem preferable because it yields more energy, yet the first is more efficient. Barring any cost to energy expenditure per se, maximizing rate would seem the better strategy.

Recent empirical evidence from a variety of species has indicated that rate maximization is a poorer predictor of foraging behavior than the efficiency criterion. Schmid-Hempel and colleagues (Kacelnik et al., 1986; Schmid-Hempel, 1987; SchmidHempel et al., 1985) measured the amount of nectar collected by honeybee workers (Apis mellifera) and found that foraging behavior was better predicted by efficiency maximization than by rate maximization. Flight speeds of parent birds provisioning dependent young also departed from rate maximizing and matched predictions of the efficiency currency (Lapland longspurs, Calcarius lapponicus: Mclaughlin and Montgomerie, 1985, 1990; black terns, Chlidonias niger. Welham and Ydenberg, 1993).

The reasons that foraging behavior should be described by maximizing efficiency are not clearly understood. One suggestion is that the risk of mortality increases with energy expenditure (SchmidHempel and Wolf, 1988; Wolf and Schmid-Hempel, 1989), while another holds that organisms have a fixed lifetime expenditure of energy (Cartar, 1992). Both ideas suggest that organisms should expend energy parsimoniously. In this paper we try to illuminate the relationships between efficiency and rate maximization and show how they may be manifestations of a more general underlying currency. The currency we use is the total net daily 
energy gain, first described by Houston (1987). We focus on constraints on the time and energy that can be allocated to foraging activities by individuals.

Time constraints are implicit in rate-maximizing currencies because, by definition, they maximize some quantity per unit time. Ecologists have readily accepted the notion of time limitation, perhaps because diel and tidal cycles are apparent to us. Maximizing efficiency implicitly acknowledges energy constraints (because it maximizes gain per unit of energy expended), but limits to the amount of energy organisms can assimilate and expend have been less widely incorporated into models. Though a high rate of energy expenditure can be maintained for short periods, it is powered by stored reserves that are depleted as exercise continues. A rate of energy expenditure is only sustainable if the organism remains in energy balance, and the sustainable rate of energy expenditure therefore cannot exceed the maximum rate of energy assimilation. The limited evidence available suggests that the maximum assimilation rate is set by digestive physiology (Karasov et al., 1986; Peterson et al., 1990). Active homeotherms may often approach or exceed such limits at some time in their lives. For example, experimental evidence shows that male Eurasian kestrels (Falco tinnunculus) routinely reach the sustainable energy expenditure limit while provisioning their broods (Masman et al., 1989; see also Bryant and Tatner, 1991).

In practice the limit to daily energy intake (and therefore to sustainable daily energy expenditure) can be estimated using Kirkwood's (1983; see also Kleiber, 1961) allometric equation. We denote this ceiling by $K$. Whatever the underlying mechanism, the existence of a limit to the sustainable energy expenditure has important implications for foraging behavior.

\section{Feeding and provisioning}

We consider two distinct foraging processes. An organism capturing and ingesting food for its own sustenance is "feeding," but an organism capturing food and delivering, sharing, or storing it for later consumption is "provisioning." (Feeders and provisioners are both foragers.) The prey captured while provisioning must be allocated between consumption by the forager (self-feeding) and delivery to the mate, offspring, or cache-site, as first recognized by Kacelnik (1984). However, most studies, including that of Kacelnik (1984), account all prey captured while provisioning in the same fashion. This is clearly inadequate because provisioners will value food for their own consumption differently than they will value food delivered, for example, to a brood. Thus, foraging situations must be distinguished as feeding or provisioning, and while provisioning, self-feeding must be accounted for separately from delivery. Distinguishing between feeding and provisioning is important because the constraints on energy intake and expenditure are different.

It is also essential that provisioning and centralplace foraging (Orians and Pearson, 1979) not be equated. Though many provisions are central place foragers, so are many feeders (e.g., diving birds). Likewise, provisioners need not be central-place
Table 1

Summary of symbols used in the models and their meanings

\begin{tabular}{|c|c|}
\hline Symbol & Meaning \\
\hline b. & $\begin{array}{l}\text { Rate of energy gain using foraging } \\
\text { strategy } i \text { (rate of delivery in provisioning } \\
\text { model) }\end{array}$ \\
\hline$B$ & $\begin{array}{l}\text { Total energetic gain over a day using } \\
\text { strategy } i \text { (total delivery in provisioning } \\
\text { model) }\end{array}$ \\
\hline b、 & Self-feeding rate of gain \\
\hline$c$ & $\begin{array}{l}\text { Rate of energy expenditure using } \\
\text { strategy } i\end{array}$ \\
\hline$C$ & $\begin{array}{l}\text { Total energetic expenditure over a day } \\
\text { using strategy } i\end{array}$ \\
\hline$c_{3}$ & Self-feeding rate of energy expenditure \\
\hline$D$ & $\begin{array}{l}\text { Proportion of total daily energy expended } \\
\text { on delivery }\end{array}$ \\
\hline$G$ & $\begin{array}{l}\text { Net energy gain over a day }\left(B_{i}-C_{1}\right) \text { using } \\
\text { strategy } i\end{array}$ \\
\hline$K$ & Maximum daily energetic expenditure \\
\hline $\boldsymbol{R}$ & Daily energetic requirement \\
\hline$T$ & Maximum foraging time available \\
\hline$t_{f}$ & $\begin{array}{l}\text { Time spent foraging (time spent } \\
\text { delivering food in provisioning model) }\end{array}$ \\
\hline
\end{tabular}

foragers; consider a mother cheetah sharing a gazelle with cubs old enough to travel with her. The central-place paradigm may be appropriate in both feeding and provisioning contexts and should not be exclusively associated with either. In the following sections we consider both these foraging processes, first building the basic model in the feeding context and then going on to incorporate modifications important in a provisioning context.

\section{Feeding model}

We imagine a forager with alternative feeding strategies, $i=1,2,8, \ldots, n$. The strategies may represent successively less profitable items to include in the diet, a choice of giving-up times, or other forging rules of thumb, travel speeds, load sizes, patch residence times, or any other aspect of feeding behavior. Each strategy specifies a rate of energy intake, $b_{i}$, and a rate of energy expenditure, $c_{i}$. Following Houston (1987), we assume that the feeding strategy chosen is the one that maximizes the total net daily energetic gain. Table l summarizes our notation. The basic feeding model is depicted in Figure 1. It incorporates the daily limit to energy assimilation, $K$, and the daily foraging time limit, $T$. We assume that feeding must cease when the total daily energy intake reaches $K$ or when time expires. The significance of the daily gain currency is that working harder (higher $b$ and $c)$ does not necessarily lead to greater total daily gains, particularly if the $K$ boundary is reached before $T$, as noted by Houston (1987).

It is convenient to identify two cases. These are suggestive of, but not identical to, the time minimizers and energy maximizers, discussed by Schoener (1971). In energy limitation (case 1), a forager's total daily energetic gain is limited by its possible energetic intake. In time limitation (case 2), the forager's total daily gain is limited by foraging time. 

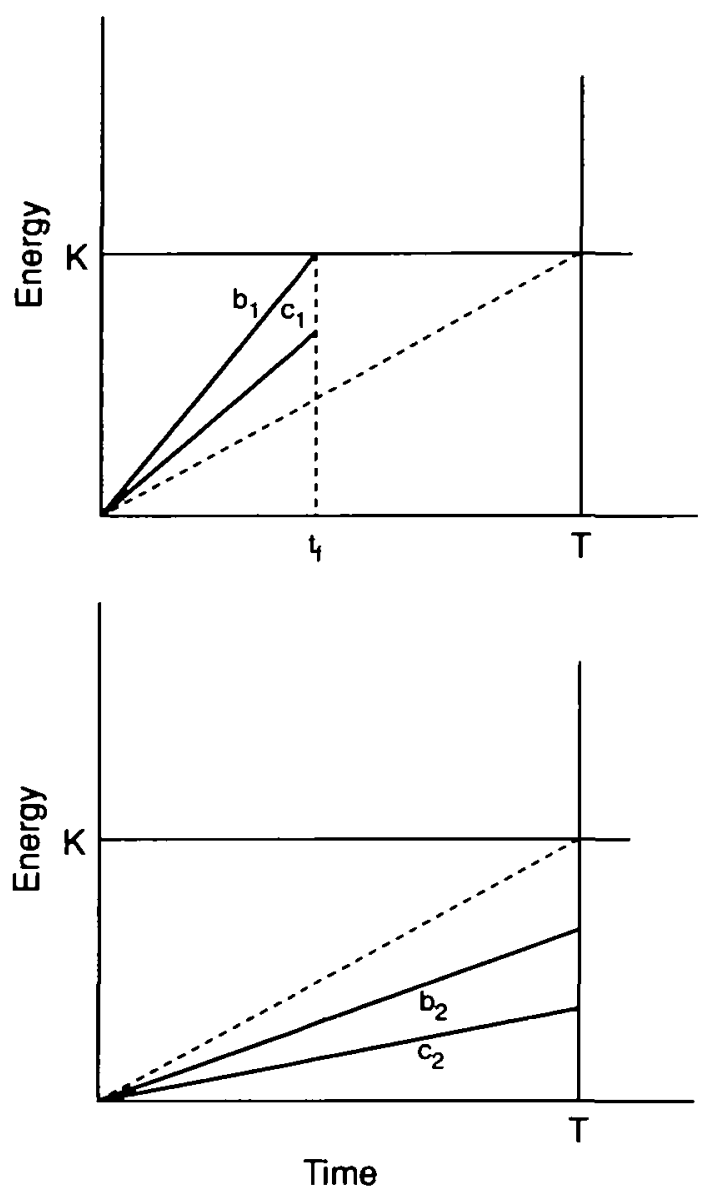

As shown in Figure 1, the cases are distinguished by the rate of encrgy intake, with $b_{2}<b_{\text {crit }}<b_{1}$, where

$$
b_{\text {crh }}=K / T \text {. }
$$

It is possible that for some foragers some strategy choices result in time limitation, while others lead to energy limitation (i.e., a limitation on the amount of energy that can be taken in and assimilated). We return to this important point below.

When $K$ sets the limit (Figure 1, upper panel) feeding time $\left(l_{f}\right)<T$, and total gross daily energetic gain $\left(B_{t}\right)=b_{t} t_{f}=K$. Total energy expenditure $\left(C_{t}\right)$ $=c_{i} t_{f}$. Considering the total net daily energetic gain,

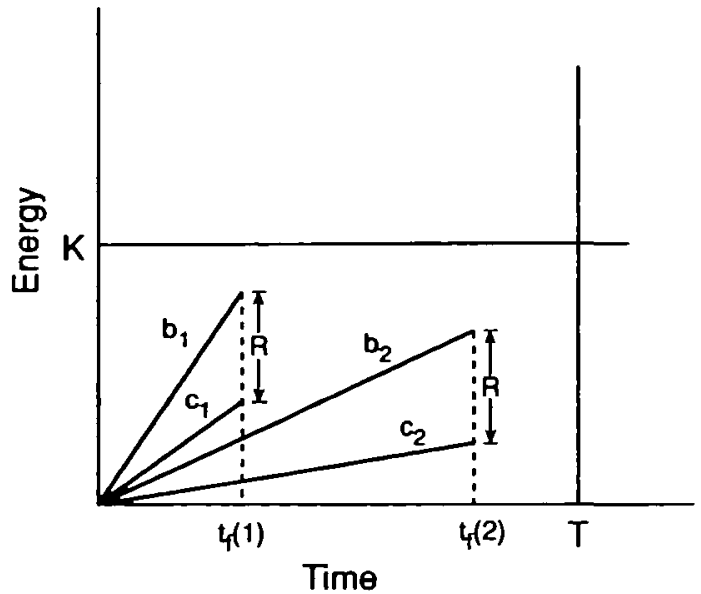

$G_{i}=B_{i}-C_{i}$, we choose $\left(b_{i}, c_{i}\right)$ to maximize $G_{i}=$ $\iota_{f}\left(b_{i}-c_{i}\right)$. Since $\iota_{f}=K / b_{i}$,

$$
G_{i}=K\left(1-c_{i} / b_{i}\right) .
$$

The term $c_{t} / b_{1}$ is the inverse of efficiency; the RHS of Equation 1 increases as efficiency rises (i.e., its inverse shrinks), and $G$, is therefore highest at maximum efficiency. Thus, as Stephens and Krebs (1986: 9) pointed out, efficiency is the currency that maximizes total gain when feeding is constrained by energy.

In the case where $T$ sets the limit to total gain (Figure l, lower panel) $B_{i}=b_{i} T$ and total energy expenditure $C_{1}=c_{i} T$. Maximum $B_{1}$ is attained by choosing $b_{i}$ to maximize $b_{i} T$, equivalent to maximizing the gross rate of energy gain. If the net energetic gain $G_{i}=B_{1}-C_{i}$ is considered, maximization involves choosing $\left(b_{i}, c_{i}\right)$ pairs to maximize

$$
G_{1}=\left(b_{1}-c_{\mathrm{i}}\right) T,
$$

which is equivalent to maximizing the net rate of energy gain while foraging.

In many cases feeding activities will not be constrained by cither time or energy, as when the forager aims to fulfill some requirement, $R$, that can be met with the time and energy available. We apply the framework developed here to analyze this situation. As before, there are strategic choices, $i=$ $1,2,3, \ldots, n$. Each has an associated gain rate, $b_{1}$, and energy expenditure rate, $c_{1}$. For any feeding time, $t_{f}$, each strategic choice gives net gain $G_{i}$, where $G_{t}=t_{N}\left(b_{i}-c_{t}\right)$. The forager can therefore choose among any combination of strategy $\left(b_{1}, c_{1}\right)$ and foraging time $\left(l_{j}\right)$ that yields a gain equivalent to the requirement, $R$ (see Figure 2). Though yielding equivalent gain, the options differ in $b_{v}, c_{r}$, and $t_{f}$, and differential fitness costs between any of these may influence the feeder's choice. For example, if foraging involves predation risk, the forager may prefer shorter $t_{f}$ (requiring higher $b_{t}, c_{t}$ ). Alternatively, faster foraging may entail higher predation risk bccause of lowered vigilance, thereby favoring lower $\left(b_{1}, c_{i}\right)$ and thus longer $t_{f}$.

\section{Provisioning model}

While provisioning, a forager collects food, consumes some itself and shares the remainder with or delivers it to another individual, or stores it for later consumption. Very few provisioning studies recognize the distinction between self-feeding and delivery, but models need to consider both explicitly because the allocation of food between them may be very important in foraging decisions. Allocation decisions have been investigated in two ways. Kacelnik (1988) and Beauchamp et al. (1991) built models in which food was directed to the parent (self-feeding) or the nestlings (delivery) using a decision algorithm bascd on the forager's lifetime reproductive success. Houston (1987) used a different approach. He assumed that provisioners must balance their own energy budget and therefore spend some time on each foraging excursion feeding themselves. Enough time is spent, on average, to recover the energetic cost of each trip. Thus the prey captured for self-feeding do not appear as "energy" in the equations, but only as a time cost. We use this approach here.

In the provisioning context we assume that pro- 
visioners aim to maximize $B_{i}$ (total amount of energy delivered), subject to meeting their own requirements. Note that $b_{n}, B_{i}$, and $t_{f}$ have changed from their meanings in the feeding context, referring in the provisioning context to the rate of delivery, the total amount of energy delivered, and the time spent in delivery (including capture of prey for delivery, but not capture of prey for self-feeding. Analogously, self-feeding does not include any components of delivery). This is consistent with their usage in foraging theory. In contrast to the feeding context, when provisioning, the total delivery $\left(B_{i}\right)$ is not limited by $K$ because a forager can often deliver much more than it could consume and assimilate itself. While provisioning there may sometimes be no effective ceiling at all (as when storing food), but the effect of a ceiling imposed by, for example, the intake capacity of small nestlings, could easily be included in the model to follow. (We omit it for simplicity.) In a provisioning context, the forager's strategy choices are limited by its total daily energy expenditure $\left(C_{\imath}\right)$ because the sustainable daily expenditure cannot exceed the maximum daily energy assimilation (described by $K$ ). To remain in energy balance the provisioner must reserve some portion of the available energy to power self-feeding. Suppose that it expends proportion $D$, of the total available energy $K$, on delivery, so that $(1-D) K$ remains for expenditure on selffeeding. The self-feeding rate of gain is $b_{a}$, and it $\operatorname{costs} c_{\mathrm{z}}$, so the net self-feeding rate is $b_{3}-c_{\mathrm{z}}$. The time required to recover the energy spent on delivery is therefore $D K /\left(b_{\mathrm{s}}-c_{\mathrm{s}}\right)$ and the energy expended is $D K c_{\mathrm{s}} /\left(b_{\mathrm{s}}-c_{\mathrm{s}}\right)$. Together the energy spent on self-feeding and delivery must equal the total available so

$$
D K c_{\mathbf{3}} /\left(b_{\mathbf{s}}-c_{\mathbf{s}}\right)+D K=K .
$$

Solving for $D$,

$$
D=\frac{1}{\frac{c_{3}}{b_{1}-c_{3}}+1} .
$$

Therefore, $D$ depends on the gains and costs of self-feeding. Increasing the cost $\left(c_{2}\right)$ or lowering the net gain $\left(b_{3}-c_{2}\right)$ decreases the value of $D$ and reduces the fraction of $K$ that can be expended on delivery.

The necessity for self-feeding constrains the provisioning strategy choices as illustrated in Figure 3. The total delivery is free to exceed $K$, as described above. However, the total daily energy expenditure on delivery cannot exceed $D K$ bccause $(1-D) K$ must be reserved to power self-feeding. Hence the line segment labeled $c_{1}$ cannot enter the shaded area above $D K$ (Figure 3 ).

The remainder of the shaded area in Figure 3 can be explained by considering that the provisioner must also reserve sufficient time for selffeeding. If it delivers prey for time $t_{f}, T-t_{f}$ remains for self-feeding, during which it must recover what it has expended on delivery, $\mathrm{C}_{i}=\mathrm{t}_{\mathrm{P}} \mathrm{c}_{i}$. Therefore, $\left(T-t_{f}\right)\left(b_{s}-c_{s}\right)=t_{f} ;$ rearranging yields

$$
\iota_{f}=\left[T\left(b_{\mathrm{s}}-c_{\mathrm{s}}\right)\right] /\left(b_{\mathrm{s}}-c_{\mathrm{s}}+c_{\mathrm{b}}\right) .
$$

As $C_{i}$ rises, more time must be reserved for selffeeding. This is illustrated in Figure 3 by the sloping right-hand boundary of the shaded portion in each
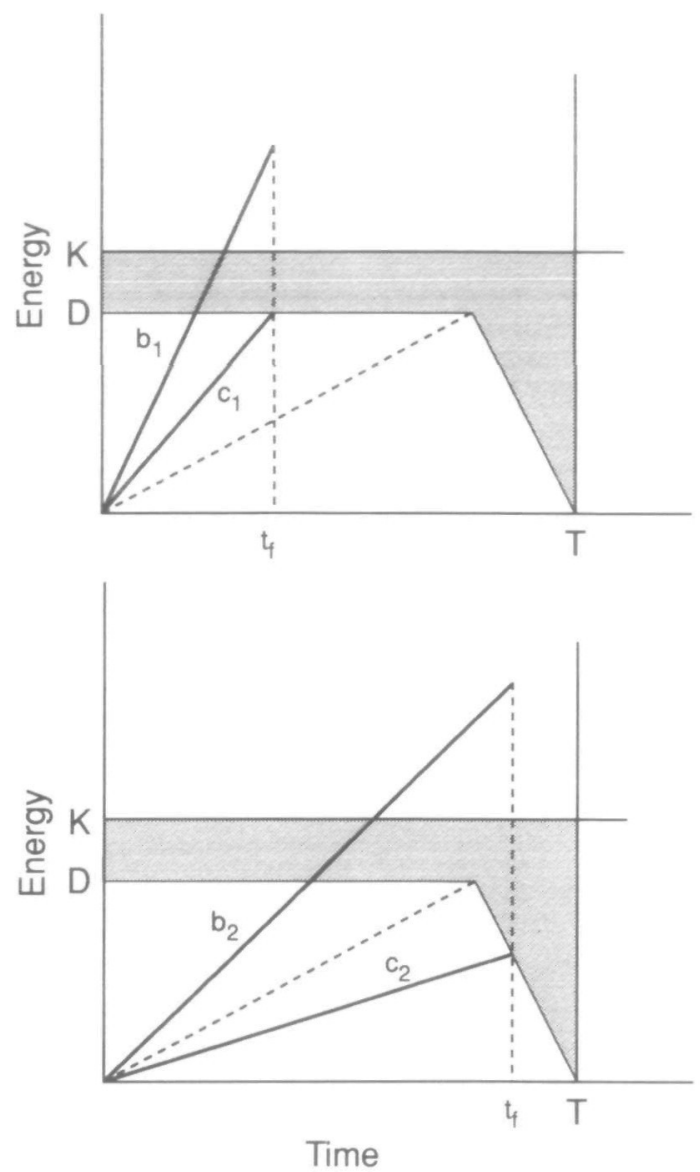

Figure 3

The provisioning model. The diagonal dotted line represents $c_{\text {rril }}$. The shaded area shows the forager's selffeeding region. (Upper panel) The energy expenditure limitation case. (Lower panel) The time limitation case. Notation summarized in Table 1. panel. The line segment labeled $c_{2}$ cannot enter this area if the provisioner is to reserve enough time for sclf-feeding.

How do these constraints influence a provisioner's strategy? As before there are two cases, corresponding to energy and time limitation, distinguished by the rate of energy expenditure, with $c_{\mathrm{f}}$ (energy limitation) and $c_{2}$ (time limitation) related as $c_{y}<c_{\text {crit }}<c_{1}\left(c_{\mathrm{crt}}\right.$ is represented in Figure 9 by the diagonal dashed line). In the energy limitation case, the forager must cease delivering prey after having expended $\mathrm{KD}$ units of energy, leaving ( 1 $D) K$ to power self-feeding so that energy balance can be maintained. The time spent delivering prey is $t_{f}=K D / c_{r}$, and the total delivery is

$$
B_{t}=b_{f} d_{f}=\left(b_{\imath} / c_{\imath}\right) K D \text {. }
$$

Because neither $K$ nor $D$ depend on $c_{i}$ or $b_{i}$, maximizing $B_{t}$ requires choosing the highest $\left(b_{t} / c_{t}\right)$ ratio, which is by definition equivalent to maximizing efficiency (Figure 3, upper panel).

We reach a different conclusion in the time limitation case. Here the forager has enough energy for self-feeding but must cease delivery before $T$ to leave enough time to recover its expended energy (Figure 3, lower panel). As before, the provisioner aims to maximize total delivery, $B_{i}=b_{i} l_{f}$. Substituting from Equation 4 and rearranging yields

$$
B_{1}=\left(\frac{b_{1}}{c_{\mathrm{s}}}\right)\left[\frac{T\left(b_{\mathrm{s}}-c_{3}\right)}{1+\left(\frac{b_{\mathrm{s}}-c_{\mathrm{s}}}{c_{\mathrm{s}}}\right)}\right]
$$


Figure 4

Provisioning in the starling (Sturnus vulgarns), based on estimates given in Houston (1987). Under time limitation, the choice of foraging strategy (patch residence time) depends on the net rate of self-feeding. As $b_{4}-c_{\text {, }}$ increases from $5 \mathrm{~W}$ to $40 \mathrm{~W}$, the patch residence time maximizing total daily energetic gain decreases from $170 \mathrm{~s}$ to $70 \mathrm{~s}$. The change in efficiency with change in choice of strategy $(b, c)$ is shown in the bottom panel, and the gross rate and efficiency maxima are indicated. (Note that $200 \mathrm{~s}$ is the largest patch time considered.)

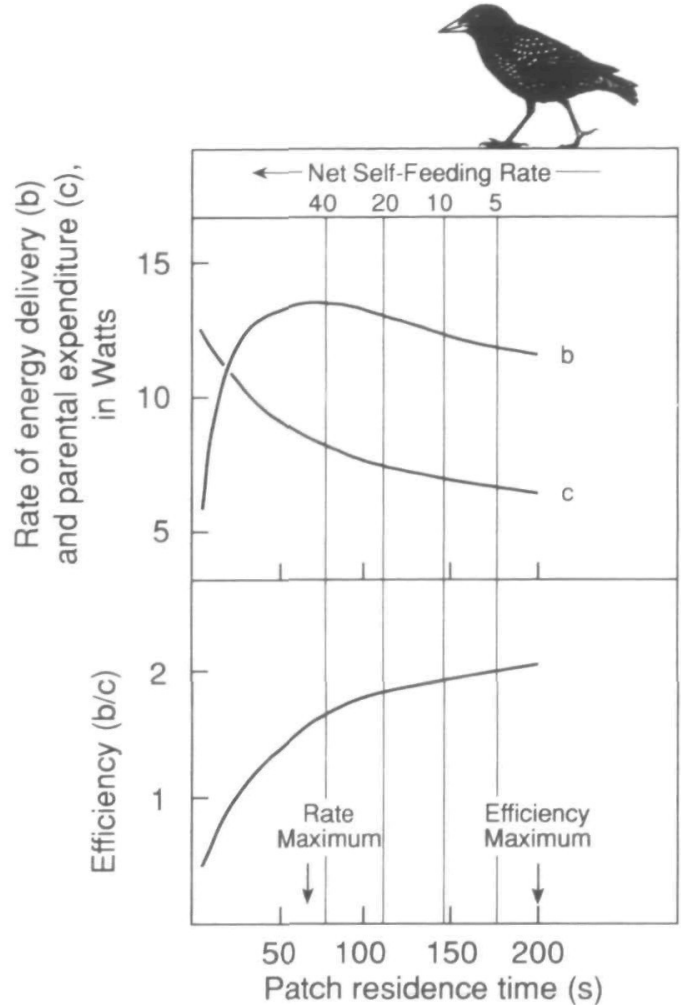

The first factor on the RHS indicates that, as before, a high $b_{t} / c_{1}$, ratio is favored. However, the second factor shows that small values of $c_{i}$ (relative to $b_{3}-c_{3}$ ) reduce $\mathrm{B}_{i}$; therefore higher values of $c_{i}$ are favored, so that more energy may be delivered before time expires. The optimal strategy therefore depends on the net self-feeding rate $b_{3}-c_{\mathbf{3}}$. When it is low (relative to $c_{i}$ ), the choice of $\left(b_{i}, c_{i}\right)$ approximates maximizing efficiency, but as it increases the choice of strategy maximizing total delivery changes. Note that our Equation 6 is equivalent to Equation 5 in Houston (1987).

A numerical example is shown in Figure 4, which depicts the rates of energy delivery and energy expenditure for a parental starling (Sturnus vulgaris) as described in Houston (1987). The figure is based on a situation in which the parent makes repeated

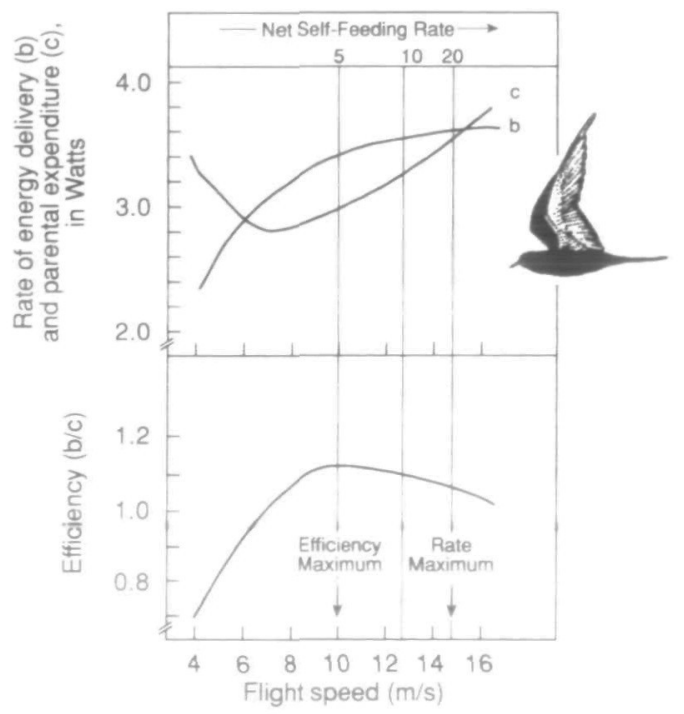

trips to collect prey in a patch and delivers them to its brood. The foraging strategy is the choice of patch-residence time that maximizes total daily delivery to the nest. The curve $b$ represents the rate of energy delivery to the brood at different patchresidence times, and $c$ represents the parent's rate of energy expenditure. Efficiency is favored under energy limitation, which is maximized at the longest allowable patch time of $200 \mathrm{~s}$. Under time limitation, the choice maximizing $B_{\text {, depends on the net }}$ rate of self-feeding, $b_{3}-c_{\mathrm{s}}$. Patch time decreases rapidly as self-feeding rate increases, but it does not reach the net rate maximizing level until it is greater than $50 \mathrm{~W}$. The patch-residence time that maximizes the total daily delivery lies between the efficiency and net rate optima, moving from the former to the latter as the net self-feeding rate increases.

A second numerical example based on the work of Welham and Ydenberg (1993) is represented in Figure 5. Here parent black terns travel from their nest to a foraging area and capture in flight a single prey item which they deliver to the nest. The foraging strategy is the choice of flight speed between nest and feeding site. By flying faster a higher rate of prey delivery is attained (curve $b$ in Figure 4), but a higher rate of energy expenditure is incurred (curve $c$ ). Under energy limitation, the highest total daily delivery is reached at the efficiency optimum. Under time limitation, the optimum depends on the net self-feeding rate $b_{\mathrm{s}}-c_{\mathrm{s}}$ and increases from the efficiency to the rate optima as it increases to $20 \mathrm{~W}$.

\section{DISCUSSION}

The simple models developed here show that, in a feeding context, maximizing the total energetic gain over a day can lead to either rate- or efficiencymaximizing behavior. The former is expected when the total daily gain is limited by time availability, the latter when limited by energy assimilation. For a provisioner aiming to maximize total daily delivcry while balancing its own energy budget, maximizing efficiency is expected when energy expenditure is limiting. The most interesting result is that under time limitation, behavior similar to efficiency maximizing is expected when the net rate of selffeeding is low relative to the rate of energy expenditure, as seen in Figures 4 and 5. As the net selffeeding rate increases, the strategy converges with that expected under rate maximizing.

Many investigators assert that parent birds provisioning altricial nestlings approach or reach the maximum daily delivery of food. Indeed, this idea is central to Lack's (1968) clutch size hypothesis. Lack stated that the limit to clutch size is normally set "by the amount of food parents can collect for the nestlings" (1968: 165). It is not clear whether Lack meant time or energy limitation, or neither. Nor have subsequent investigators clarified the issue, though some (e.g., Drent and Daan, 1980) are clear in their hypothesis that it is energy, rather than time, that is limiting. In fact, the two are closely related and may in practice often be difficult to distinguish. This can be visualized by considering strategy 2 in Figure 3 in which a provisioner's total daily delivery is time limited. By working harder (e.g., flying or walking faster), the provisioner may 
be able to increase the delivery rate, at the expense of increasing its own energy expenditure. As the provisioner works harder, the rate of energy expenditure, $c_{\nu}$ rises until it reaches $c_{\text {cru }}$. At any higher level of work it would become energy limited (as opposed to time limited). Whether the forager would be time- or energy-limited therefore depends on the strategic options (the $b_{i}, c_{i}$ pairs), with some being time limited and others being energy limited. Equation 5 shows that the optimal rate of energy expenditure of a time-limited provisioner is higher than that predicted by the efficiency-maximizing currency, and may lie close to $c_{\text {crit }}$. In such cases, time and energy limitation would be hard to distinguish.

Quantitative tests of foraging models that have derived predictions for both the rate and efficiency maxima have found that the data often lie close to the predictions of maximizing efficiency. Kacelnik (1984) studied the foraging of parental starlings. The starlings flew to a feeding table where they obtained prey on a decelerating schedule (each successive prey took longer to arrive), and then delivered the prey to their nestlings. Kacelnik compared his observations of the number of prey collected to predictions from four foraging currencies, including efficiency. The efficiency currency did not do as well as the currency Kacelnik called "family gain" (1984: Figure 3), but it still matched predictions quite well. Schmid-Hempel et al. (1985) studied honeybees loading nectar from artificial flowers and made predictions about the number of flowers visited based on the net energy intake rate and efficiency-maximizing currencies. Their results (Schmid-Hempel et al., 1985: Figure 1) clearly match the efficiency predictions (see also Schmid-Hempel, 1987; Wolf and Schmid-Hempel, 1990) and diverge from the net energy rate predictions. McLaughlin and Montgomerie (1990) and Welham and Ydenberg (1993) studied the flight speeds of parental birds. The studies made predictions for both the rate and efficiency currencies, and both show good agreement with the latter.

The correspondence between the results of these central-place foraging studies and the predictions of the efficiency-maximizing currency arose, we hypothesize, because in all these studies the foragers were provisioning, and they adopted efficient or near-efficient behavior, thereby maximizing total daily delivery. We are not able to ascertain whether the foragers in these studies were time or energy limited, or neither. An experiment to test the model explicitly would manipulate the net rate of selffeeding independently of the collection of food for delivery. The prediction is that the choice of foraging strategy $\left(b_{i}, c_{i}\right)$ would change from the efficiency optimum (at low self-feeding rates) in the direction of the rate optimum (as net self-feeding rate increases). A particularly valuable approach would be to compare the behavior of known individual foragers in an experimental set-up that could be used in different foraging contexts. For example, some foragers may be energy limited during one part of the year, but time limited at another. Hence we would predict efficient behavior in one context but rate-maximizing behavior in the other.

Our models contain several abstractions that need to be considered. The most important of these is that we represent $K$ as a limit to daily energy as- similation. Although this is how the allometric equations of Kleiber (1961) and Kirkwood (1983) present the limit, it is more accurate to think of $K$ as a limit to the rate at which energy can be assimilated. The time and energy limits discussed in our models might be better characterized as "intake" and "processing" rate constraints. Our models also simplify the forager's day. The figures imply a single transition during the day from foraging to resting or from delivery to self-feeding. In fact, this is likely to happen many times. In the case of provisioners, some portion of many of the foraging excursions may be devoted to self-feeding. Further realism could be added by considering that many provisioners may subsidize energetic expenditure by means of a previously accumulated fat store, which would allow the daily energy expenditure to rise above the sustainable limit for some period.

The realism we lose by ignoring such aspects of the biology allows us to gain enough simplicity to make predictions interesting enough to warrant further investigation. The models underscore differences between feeding and provisioning that have not been widely recognized by foraging theory and that we believe may be very important. They also provide a good hypothesis to explain why previous studies of provisioners have so often found efficiency rather than rate-maximizing behavior.

Comments by an anonymous referee, Bruno Ens, LucAlain Giraldeau, Don Hugie, Dave Stephens, and Simon Fraser University's lunchtime seminar Les Ecologistes are gratefully acknowledged. This work was supported by a Natural Sciences and Engineering Research Council (NSERC) operating grant to R.C.Y., an NSERC Postdoctoral Fellowship to G.B., and grants from the Swiss National Science Foundation to P.S.-H. The work was completed while P.S.-H. and R.S.-H. were on leave at Simon Fraser University.

\section{REFERENCES}

Beauchamp G, Ens BJ, Kacelnik A, 1991. A dynamic model of food allocation to starling (Sturnus vulgarn) nestlings. Behav Ecol 2:21-37.

Bryant DM, Tatner $P, 1991$. Intraspecies variation in avian cnergy expenditure: correlates and constraints. Ibis 133: 236-245.

Cartar RV, 1992. Morphological senescence and longevity: an experiment relating wing wear and life span in foraging bumble bees. J Anim Ecol 61:225-231.

Drent RH, Daan S, 1980. The prudent parent: energetic adjustments in avian breeding. Ardea 68:225-252.

Fagerstrōm T, Moreno J, Cartson A, 1983. Load size and energy delivery in birds feeding nestlings: constraints on and alternative strategies to energy-maximization. Oecologia 56:93-98.

Houston AI, 1986. The optimal flight velocity for a bird exploiting patches of food. J Theor Biol 1 19:345-362.

Houston AI, 1987. Optimal foraging by parent birds feeding dependent young. J Theor Biol 124:251-274.

Kacelnik A, 1984. Central-place foraging in startings (Stumus rulgaris): I. Patch residence time. J Anim Ecol 53:283-299.

Kacelnik $A, 1988$. Short-term adjustments of parental effort in starlings. In: Acta XIX Congressus Internationalis Ornithologici (Ouellet H, ed). Ottawa: University of Ottawa Press; 1849-1856.

Kacelnik A, Houston AI, Schmid-Hempel P, 1986. Central-place foraging in honey bees: the effect of travel time and nectar flow on crop filling. Behav Ecol Sociogiol 19:19-24. 
Karasov WH, Phan D, Diamond JM, Carpenter FL, 1986. Food passage and intestinal nutrient absorption in hummingbirds. Auk 103:453-464.

Kirkwood JK, 1983. A limit to metabolizable energy intake in mammals and birds. Comp Biochem Physiol 75A: 1-3.

Kleiber $\mathrm{M}, 1961$. The fire of life: an introduction to animal energetics. New York: John Wiley.

Lack D, 1968. Ecological adaptations for breeding in birds. London: Methuen.

Masman D, Dijkstra C, Daan S, Bult A, 1989. Energetic limitation of avian parental effort: field experiments in the kestrel (Faleo innunculus). J Evol Biol 2:435-455.

McLaughlin RL, Montgomerie RD, 1985. Flight speeds of central place foragers: female Lapland longspurs feeding nestlings. Anim Behav 33:810-816.

McLaughlin RL, Montgomerie RD, 1990. Flight speeds of parent birds feeding nestlings: maximization of foraging efficiency or food delivery rate? Can J Zool 68: 2269-2274.

Montgomerie RD, Eadie J, Harder LD, 1984. What do foraging humming birds maximize? Oecologia 63:357363

Orians GH, Pearson NE, 1979. On the theory of centralplace foraging. In: Analysis of ecological systems (Hom DJ, Mitchell RD, Stairs GR, eds). Columbus, Ohio: Ohio University Press; 154-177.
Peterson CC, Nagy KA, Diamond J, 1990. Sustained metabolic scope. Proc Nat Acad Sci USA 87:2324-2328.

Schmid-Hempel P, 1987. Efficient nectar-collection by honeybees: I. Economic models. J Anim Ecol 56:209218.

Schmid-Hempel P, Kacelnik A, Houston AI, 1985. Honeybees maximize efficiency by not filling their crop. Behav Ecol Sociobiol 17:61-66.

Schmid-Hempel P, Wolf T, 1988. Foraging effort and life span of workers in a social insect. J Anim Ecol 57:509521.

Schoener TW, 1971. Theory of feeding strategies. Annu Rev Ecol Syst 2:969-404.

Stephens DW, Krebs JR, 1986. Foraging theory. Princeton, New Jersey: Princeton University Press.

Welham CVJ, Ydenberg RC, 1993. Efficiency maximizing in parent black terns. Ecology 74:1853-1901.

Wolf T, Schmid-Hempel P, 1989. Extra loads and foraging life-span in honey bee workers. J Anim Ecol 58 943-954.

Wolf T, Schmid-Hempel P, 1990. On the integration of individual foraging strategies with colony ergonomics in social insects: nectar-collection in honeybees. Behav Ecol Sociobiol 27:103-111. 